patients were seen by the medical officers. How we are hampered by the fact that we have not one single bed at our disposal, I leave you to imagine. This hospital was founded on Monday, November 4th, 1884, by Captain Moorsom, William Chance, Robert Martineau, and Mr. William Dimpton, who was its first surgeon, an office which he held till his death in 1859. After this the hospital passed through many vicissitudes, its premises being changed several times. In due course its usefulness was further extended by the treatment of cases of diseases of the throat. In 1884 it was removed to its present premises-7, Great Charles Street-premises a great improvement upon its previous habitation, but still far from being worthy of the great speciality which it represents. I should have said that in 1884 its staff consisted of four medical officers. The day is fast approaching when it will have a more suitable home, as a building is now being erected in the centre of the town to accommodate the increasing number of out-patients, and to provide for a small number of in-patients, for which, as our means grow larger, increased accommodation will be provided. So much for this hospital. The General Hospital has also a throat and ear department under the care of one of its assistant-physicians and one of its assistant-surgeons.

These, then, are the facilities which exist in Birmingham for the study and teaching of rhinology and laryngology at the present time. Unfortunately, for reasons into which I need not enter, the Ear and Throat Hospital is not used by the students of the Birmingham Medical School. This I regard as a great misfortune to our speciality, and to the medical officers themselves, as I believe that the presence of students lends aid to the zest and ability with which the medical officers of a hospital discharge their duties. Now, although I am quite ready to admit that it is to special hospitals that the advances made are principally due, and that to their officers more than to those in charge of special departments in general hospitals, the popularity of thelaryngoscope was due, and that special hospitals were founded because general hospitals were too slow in meeting modern requirements, yet I sincerely trust that no more special hospitals will be tounded, but general hospitals, which profess to educate students, shall have well equipped laryngological and rhinological departments, officered by competent specialists, who shall be placed on terms of equality with the physicians and surgeons.

Now I fear that to some members of the Section these may appear very heretical opinions, which ought to consign me to the laryngological stake. But with all due deference to my opponents, I am prepared to defend this statement with what I believe to be competent arguments. I think you will all grant that every student, before he obtains the diploma which permits him to practise, should at least have a fairly proficient knowledge of the use of the laryngoscope and rhinoscope-a knowledge which should be tested (I do not say severely) at his final examination. Now how is he to obtain this proficiency? The answer suggests itself-by attending a course of instruction upon these subjects, under the care of a competent teacher. Now, as President of the Clinical Board of this town which has charge of the clinical teaching at the Amalgamated Hospital, and as a lecturer at Queen's College, I know that the burden laid upon the back of the student is as much, or even more, than he can bear. The number of lectures he is compelled to attend, the amount of clinical work he has to perform, the increased and increasing severity of the examinations, leave little time upon his hands in which to visit special hospitals. If, when attending at his general hospital, he finds the speciality upon the spot, he is able to give his attention to it without waste of time in going from one hospital to the other. I would not wish for one moment to detract from the value of special hospitals, but I would ask their officers to give their powerful aid in impressing upon the hospital authorities the necessity, in the interest of the public, of providing special departments where the students may gain the necessary information; and upon the examining bodies the absolute importance of compelling students to attend a short course on laryngology and rhinology which shall render them competent to treat those diseases in which a knowledge of the laryngoscope and rhinoscope are absolutely necessary. It must have been the lot of almost every member of this Section to have met with cases in which a little knowledge on the part of the practitioner in the outset of the disease would have spared the patient weeks, possibly months, of suffering.

In conelusion, I again offer you all a most hearty welcome, and I will no longer stand between you and the interesting papers which will now be read and, I hope, receive a full and adequate discussion in this Section.
AN ADDRESS or

\section{THE PRESENT POSITION OF ANTISEPTIC SURGERY.}

Delivered before the International Medical Congress at Berlin, August, 1890.

By Sir JOSEPH LISTER, Bart., F.R.S., Professor of Clinical Surgery in King's College.

Mr. President and Gentlenke,-At the International Congress in London, in 1881, Robert Koch demonstrated in King's College, his then new method of cultivating microbes upon solid medis. The illustrious veteran Pasteur was present at the demonstration; and at its conclusion exclaimed "C'est un grand progrès, Monsieur." How vast have been the extensions of our knowledge which have resulted from that great step in advance! Of these none perhaps have been more striking than Koch's own brilliant discovery of the cholera microbe-picked out with unerring precision by his beautiful method from among the multitude of bacteric forms that people the intestinal contents, and grown and studied with as much definiteness as if it were a cabbage or a rose.

But while we have during the last nine years learned so much more of the nature and habits of the micro-organisms which invade our bodies, a new and surprising light has been thrown within the same period upon the means by which the living animal defends itself against their assaults. This we owe to the eminent naturalist Metchnikoff, who, having long cartfully studied intracellular digestion in the amoboid cells which form the main mass of the bodies of sponges and other humble organisms, was prepared to observe and rate at its true value an analogous process in the wandering leucocytes of vertebrata. He found that these migratory cells, with whose amœboid movement we have been long familiar, feed also like amœbæ, and while almost omnivorous in their appetites, have a special fondness for bacteria; taking them into their protoplasmic substance and digesting them, thus preventing their indefinite propagation among the tissues. The cells which exercise this devouring function be termed phagocytes.

Various objections have been urged against Metchnikoff's views ; but so far as I am able to judge, he has met these effectively by his masterly series of researches; and his observations have been confirmed and extended by several independent investigators. ${ }^{1}$ For the sake of those among my audience who may chance not to be familiar with Metchnikoff's work, I am tempted to relate briefly some of his experiments. The green frog, below the temperature of $20^{\circ} \mathrm{C}$. $\left(68^{\circ} \mathrm{F}\right.$.) is incapable of taking anthrax : the bacilli of that of 20 cher in of that animal. To what was this immunity of the frog to anthrax due? Were its juices an unfit pabulum for the microbe, or was the phagocytic action of its leucocytes the explanation? In the hope of solving this question Metchnikoff formed a tiny bag out of the pith of the reed, and having placed in it some spores of anthrax, closed the bag and inserted it beneath a frog's skin. The pith wall of the bag allowed the animal's lymph to penetrete by diffusion, but excluded the leucocytes: and the result was that the spores sprouted and grew into luxuriant threads of anthrax in the lymph. which was thus proved to be a suitable medium for the growth of the bacillus. Meanwhile under another part of the skin of the same frog had been placed a small piece of the spleen of an animal that had just died of antbrax and contained the microbe in its most virulent form; but there, the leucocytes having free access, no growth occurred.

Another experiment on the same principle was still more instructive. It consisted in introducing the spores of anthrax into the anterior chamber of the eye of a frog, which, as we have seen, is naturally insusceptible of the disease; and also into that of a sheep and of a rabbit rendered insusceptible artificially by "vaccination" with Pasteur's attenuated virus. The aqueous 1 See for example Dr. Tchistovitch, Annales de l'Institut Pasteur, 25e Jullet 1899, and Dr. Armand Ruffer, BRITIsH Medic 
humour of the healthy eye contains few if any leucocytes to interfer $\theta$ with the perfect transparency essential to vision. Accordingly, the spores sprouted and grew for a while freely in the anterio chamber. Meanwhile, the growth of the bacillus occasioned irritation to the eye, resulting in the immigration of a constantly increasing number of leucocytes, producing turbidity and, in time, hypopion. If a drop of the aqueous humour was withdrawn at an early period after the commencement of the experiment, and examined with the microscope, it was found to contain anthrax bacilli, some of them free in the liquid, but others enclosed in the bodies of leucocytes. But a drop taken after a longer period had elapsed showed no free bacilli, all being now within the leucocytes, and exhibiting signs of degeneration in various degrees as the result of their advancing digestion. Finally the anthrax disappeared entirely and the eye cleared up, the animal in al cases remaining healthy, although inoculation into the aqueous humour proved a peculiarly deadly mode of infecting a susceptible animal. ${ }^{2}$

Here we see that the inflammation excited by the microbe becomes, through the medium of the leucocytes, the cause of its destruction. How little can the lamented Cohnheim have dreamed that his observation of the emigration of leucocytes in inflammation would prove to have so fur-reaching a bearing upon the pathology of infective diseases?

I have brought before you two samples of the kind of evidence upon which the phagocyte theory rests, and if we accept it, as I believe we must, it serves at once to explain much that has hitherto been mysterious in the relations of micro-organisms to wounds. Take, for example, that which the surgeon makes for the cure of hare-lip. Its posterior edge is perpetually bathed with the saliva, which contains many kinds of septic bacteria. But these do not enter and people the fibrin that glues together the cut surfaces, as they infallibly would do if those surfaces were composed of glass or any other chemically inert material destitute of life. It has long been very evident that the living tissues exerted a potent influence in checking bacteric development in such a wound; but what was the nature of that influence? This used to be an enigma, but now receives its natural explanation in the phagocytic action of the cells that crowd the lymph soon after its effusion.

At the London Congress I brought forward an experiment which proved that a blood clot within the body may exert a powerful anti-bacteric agency. I will not repeat the details of that experiment further than to say that a very small piece of linen cloth soaked with putrid blood was mounted by means of silver wire in the interior of a short glass tube open at both ends, which was slipped into the jugular vein of a donkey, and kept in position between two ligatures. After two days the venous compartment was removed, and coagulum within it investigated. In and near the glass tube it was in a state of advanced putrefaction, as was indicated by its foul odour and greatly altered appearance; and microscopic $\in x a m i n a t i o n$ showed that it abounded with bacteria. But near the wall of the vein it looked to the naked eye like a recent clot; I could not detect in it any putrid odour, nor could I discover bacteria with the microscope. ${ }^{3}$ Stained sections of these outer parts of the coagulum, made after hardening in alcohol, showed great multitudes of cells differing from one another in size and other characters, just as is of ten the case with Metchnikoff's phagocytes. I suppose that these cells must have been in some way or other the anti-bacteric agents, but how, I could not imagine. The phagocyte theory clears up the mystery.

By means of this same theory we can account for what would otherwise have seemed to me incomprehensible-the use, without evil consequences, of silk ligatures - which have not been subjected to any antisepic preparation. We learn from the experiments of Ziegler and others that leucocytes soon penetrate very thin spaces between plates of glass or other chemically inert foreign bodies inserted among the tissues. And we can understand that they may creep into the intervals between the fibres of a silk thread and destroy any microbes that may have lodged there before they have had time to develop serious septic mischief. But there must surely be a limit to the thickness of the threads. No one, I imagine, would feel justified in leaving in the peritoneal cavity an unsterilised cord as thick as a finger. Dr. Bantock, whose remarkable series of successful ovariotomies may seem to justify his practice, does not, I believe, prepare his ligatures antiseptically ; and I understand that he uses, for tying the pedicle of

2 See Annales de l'Institut Pasteur, 25 Juillet, 1887, pp. 326, 327.

3 See Transactions of the London International Medical Congress. the tumour, silk twist of so strong a nature that it can be trusted to bear the needful strain, with a diameter of only about 1.30 inch. But it would surely be wiser to sterilise even so slender a cord. Who can say that septic mischief may not occasionally lurk in the ligature in a form which may baffle the phagocytes?

The success in abdominal surgery achieved by Bantock and Lawson Tait, without, it is said, the use of antiseptic means, proves a stumbling block to some minds. But in truth the practice of these surgeons is by no means conducted without antiseptic precautions, nor would they, I am persuaded, desire that such an impression should prevail. Both are scrupulously careful in the purification of their sponges, and if there is one thing more important than another in the antiseptic management of wounds of the peritoneum it is the avoidance of impure sponges. Both observe the strictest cleanliness-which is surely an antiseptic precaution-for it owes its virtue to the fact that it presents the septic organisms in the smallest possible numbers and thus reduces their power for evil to the utmost that can be done by any measures that are not germicidal. Both these surgeons also wash out the peritoneum with water so as to get rid of coagula without injuring the peritoneal surface by rubbing it with sponges, and this is done in order to avoid the risk of sepsis in residual clots. The drainage of the peritoneum is another antiseptic measure, and Dr. Bantock, I am informed, has the sponges which absorb the serum wrung out of sulphurous acid, and changes them very frequently.

This is a department of surgery in which I have had but little personal experience. But I can see that while the measures to which I have referred are, so far as they go. highly valuable, it must be in itself a very desirable thing to avoid the direct application to the peritoneum of strong and irritating antiseptic solutions. But now that we are all agreed that microbes are the evil with which we have to contend, it is surely wiser to ensure by germicidal means their entire absence from our hands and instruments rather than trust to the most perfect cleanliness in the ordinary sense of the term. And if water is used for washing out the peritoneum, prudence seems to me to dictate that it ought to be freed entirely from living organisms, if this can be done without making it irritating. This object is, I believe, aimed at by Dr. Bantock by boiling the water before using it, but I would advise as more effectual an extremely weak solution of corrosive sublimate, such as 1 in 10,000, which, as Koch has taught us, may be implicitly trusted as antiseptic, while it is not appreciably irritating and involves no risk of mercurial poisoning.

In general surgery the direct application of strong antiseptic solutions is not attended with the same disadvantages as in operations in the peritoneal cavity. My practice for some time past has been to wash the wound, after securing the bleeding points, with a pretty strong solution of corrosive sublimate (1 to 500 ) and irrigate with a weaker solution (1 to 4,000) during the stitching, and I have had no reason to complain of the results. To this, however, I must make one marked exception. When applied to the healthy synovial membrane of a joint, the 1 to 500 sublimate lotion produces inconvenient irritation, and therefore, when opening an articulation - as for suturing a transverse fracture of the patella-I abstain from the washing, and, as a substitute, have hitherto irrigated during the whole operation with the weak solution ( 1 to 4,000$)$.

And yet I must confess that I have for a long time doubted whether either the washing or the irrigation was really necessary. These doubts have been raised partly by experimentssome of which I mentioned at the London Congress-which had proved to me that normal blood and serum, and even pus, were by no means favourable soils for the growth of microbes in the form in which they are present in the air-and partly by reflection upon the experience we had when we used the carbolic spray.

As regards the spray, I feel ashamed that I should have ever recommended it for the purpose of destroying the microbes of the air. If we watch the formation of the spray and observe how its narrow initial cone expands as it advances, with fresh portions of air continually drawn into its vortex, we see that many of the microbes in it, having only just come under its influence, cannot possibly have been deprived of their vitality. Yet there was a time when I assumed that such was the case, and, trusting the spray implicitly as an atmosphere free from living organisms, omitted various precautions which I had before supposed to be essential. Thus, in opening the pleura in empyema for the purpose of evacuating the pus and introducing a drainage 
tube, and afterwards in changing the dressings, I had previously applied over the opening a piece of cloth steeped in an antiseptic lotion to act as a valve and prevent the entrance of air during inspiration. But under the spray I omitted the valve and allowed the air to pass freely in and out of the pleural cavity, although I used the spray at such a distance from the producing apparatus that it was dry and transparent, with the particles of carbolic solution necessarily widely separated from each other. And these particles cannot have been in more than instantaneous contact with much of the dust before it was drawn within the chest, and securely protected by the pus or serum there from any further action of the antiseptic. It is physically impossible that the microbes in such dust can have been in any way whatever affected by their momentary presence in the spray.

Yet we did not find our results in the treatment of empyeme rendered worse by this false confidence in the spray. There are few more beautiful things in antiseptic surgery, as contrasted with the results of former practice, than to see the abundant purulent contents of the pleural cavity give place at once to a serous effusion, rapidly diminishing from day to day till, the opening being allowed to close, the pleura, restored to its healthy condition, resumes its normal function of absorbing gases; and, as the natura vacuum within it becomes re-established, the atmospheric pressure blows up the contracted lung, and brings it again into contact with the chest wall unimpaired in its dimensions. Such a case we had witnessed before the days of the spray, and such we continued to see during its use.

If, then, no harm resulted from the admission day after day of abundant atmospheric organisms to mingle unaltered with the serum in the pleural cavity, it seems to follow logically that the floating particles of the air may be disregarded in our surgical work; and, if so, we may dispense with antiseptic washing and irrigation, provided always that we can trust ourselves and our assistants to avoid the introduction into the wound of septic defilement from other than atmospheric sources.

Since we abandoned the spray, three years ago, we have been careful to compensate for its absence, not only by antiseptic washing and irrigation, but by surrounding the seat of operation with widespread towels wrung out of an antiseptic solution. For the spray, though useless for the object for which it was originally designed, had its value as a diffuse and perpetual irrigator, maintaining purity of the surgeon's hands and their vicinity as an unconscious caretaker. But if besides the spray we give up all washing and irrigation of the wound, our vigilance must be redoubled. Yet I believe that, with assistants duly impressed with the importance of their duties, the task would prove by no means difficult

I have not yet ventured to make the experiment on any large scale, though I have long had it in contemplation. It is a serious thing to experiment upon the lives of our fellow-men, but I believe the time has now arrived when it may be tried. And if it should succeed, then perhaps may be fulfilled my early dream. Judging from the analogy of subcutaneous injuries, I hoped that a wound made under antiseptic precautions might be forthwith closed completely, with the line of union perhaps sealed hermetically with some antiseptic varnish, and bitter was my disappointment at finding that the carbolic acid used as our antiseptic agent induced by its irritation such a copious effusion of bloody serum as to necessitate an opening for its exit; hence came the drainage of wounds. But if we can discard the application of an antiseptic to the cut surfaces, using sponges wrung out of a liquid that is aseptic but unirritating, such as the 1 to 10,000 solution of corrosive sublimate, we may fairly hope that the original ideal mav be more or less nearly attained.

We have already made of late considerable approaches towards it. Our wounds being no longer subjected to the constant irrigation of the spray, and carbolic acid having given place to the less irritating, though more efficient, solutions of corrosive sublimate, serous discharge is much less than formerly, and less drainage is required. In many small wounds whese we used to find drainage imperative we omit it altogether, and in those of larger extent we have greatly reduced it. Thus, after removing the mamma and clearing out the axilla, J now use one short tube of very moderate calibre, where I used to employ four of various dimensions. But it would be a grand thing if we could dispense with drainage altogether; without applying the very firm elastic compression adopted by some surgeons, which, besides involving the risk of sloughing of parts of low vital power, with the chance that it may after all fail in its object, proves often extremely irksome to the patient.
It remains for me to say a few words regarding the best form of external dressing. Some surgeons have thought that simplicity and efficiency may be combined in the maximum degree by the use of cotton-wool sterilised by heat. But though it may be a simple thing to heat the wool appropriately by means of suitable apparatus in a public institution, for the ordinary practitioner it would be impracticable. And as regards efficiency, I need bardly remark that cotton-wool, merely aseptic, can only exclude septic mischief when it is in the dry state. When it is soaked to its external surface with a copious discharge, it must be liable to become septic en masse. And however well we may succeed in the future in diminishing or abolishing discharge from wounds made by the surgeon, there must always remain cases in which it will occur in greater or less amount.

Contused wounds, for example, into which dirty material of one kind or another has been introduced before they are seen by the surgeon, must be purified by the use of powerful antiseptic means, and must, for a while, discharge freely. The same is to be said of cases in which we make the attempt, often with signal success, to restore an aseptic condition in a part affected with septic sinuses. Again, there are abscesses in which, in the present state of our knowledge, we cannot avoid the occurence of considerable serous oozing, and in which a perfectly trustworthy antiseptic dressing is a matter of life and death. And whenever discharge is considerable, it is essential that the dressing be of a kind which will not permit the development of septic organisms in it, although it be saturated throughout; and this can, I believe, only be attained by the use of chemical antiseptic substances.

I have for some time past employed for this purpose a combination of the two cyanides of zinc and mercury, which appears to fulfil the requisite conditions of antiseptic efficacy and due storage of the agent in spite of free discharge, together with absence of irritating properties. Having already published on this subject, I will not detain the members of the Congress with details regarding it, further than to say that since the date of that publication Professor Dunstan, of the London Pharmaceutical Society, has devised means by which the substance can be prepared in a perfuctly definite manner, and containing twice as great a percentage of the cyanide of mercury us that which we have hitherto used; and, as I have ascertained that the cyanide of mercury is the more important ingredient antiseptically, and also that its larger amount in Dunstan's material does not make the salt irritating, we may fairly regard the new preparation as an improvement. And yet we have had no need to complain of this substance in the form in which we have used it hitherto. Those who have followed my practice at King's College Hospital during the year and a half in which this dressing has been employed will agree with me that we have secured a constancy of aseptic results which has more than ever justified the performance of operations once quite unwarrantable.

In thus referring to my own work, I do so, believe me, in no boastful spirit; but in the hope of stimulating some of those whom I address on this memorable occasion to more thorough earnestness in pursuit of the great objects of antiseptic surgery.

Tha Russian Government has recently forbidden public séances of hypnotism, and the application of it to the treatment of disease is only allowed in the presence of several medical men.

The Cannibals of the Odbanghi.-Father Augouard, apostolic pro-vicar of the Oubanghi, contributes to the Missions Catholiques, the narrative of a journey which he has just made from Loango to the Oubanghi, an affluent of the Congo. In the Oubanghi country human flesh is an article of regular consumption, not a day passing without a village immolating some victim destined to provide a feast. Sometimes it is the death of a chief, at others the celebration of a victory, at other times the arrival of a piece of good news, which serves as a pretext, and one chief will vie with another to see which can immolate the most victims. These savages regard human flesh as a dainty morsel, and prefer it to any other food, considering that it is a noble kind of food, far superior to that of animals. When told that it was horrible to eat their fellow-creatures, they simply replied:- "No, it is delicious with salt and spices." When Father Augouard went on to point out to them the difference between man and the animals, and to say that if they fell into the hands of their enemies they might be eaten in their turn, all that they said was that that was the fate of war, and that just as man was nobler than the animal, so his flesh was " more noble to eat." 